\title{
ROAD USE BEHAVIOUR OF URBAN PRIMARY SCHOOL CHILDREN IN GHANA: CASE STUDY OF ABLEKUMA SOUTH EDUCATION CIRCUIT OF METROPOLITAN ACCRA
}

\author{
I. K. Yankson*, N. K. Nsiah-Achampong, And A. Yeboah-Sarpong \\ (I. K. Y. \& N. K. N-A.: CSIR-Building and Road Research Institute \\ (BRRI), Kumasi, Ghana; \\ A. Y-S.: University of Cape Coast, Cape Coast, Ghana). \\ *Corresponding author's email: kofi.yankson@gmail.com
}

\begin{abstract}
School children form majority of injured children on Ghanaian roads. The objective was to observe the road use behaviour of public primary school pupils in Ablekuma Education Circuit, Accra. This unobtrusive observational study targeted Primary one to six pupils. Five behaviours were studied: Walking while crossing road; Stopping at the kerb; Looking left-right-left before crossing; Keep looking left-right-left while crossing and Facing traffic while walking. 882 pupils on their way to or from school were observed from eight schools. A little over two in three children stopped at the kerb before crossing the road while almost three in four children looked for cars before stepping off the kerb. A little over three in four children walked while crossing and less than one in four children kept looking while crossing. Not looking for cars before crossing, not facing on-coming traffic and not keeping looking for cars while crossing, were more associated with boys than girls ( $p<0.001 ; 95 \% \mathrm{CI}$ in all cases). Girls behaved significantly more safely than boys. In stopping at the kerb, there was no difference in gender behaviour ( $\mathrm{p}$ $<0.135 ; 95 \% \mathrm{CI}$ ). Child Road Safety Education in Schools and Communities is recommended.
\end{abstract}

Keywords: Child, road use behaviour, looking left-right-left, keep looking, stopping at the kerb, road safety education

\section{Introduction}

No one is born knowing how to use the road system. Children and young people have a high involvement in road crashes, which is a worrying occurrence and needs urgent attention. Children use the road as passengers, pedestrians, bicycle riders and public transport users. A child's risk for pedestrian injury is related to their overall exposure to traffic.

The World Health Organization (WHO) reports that injury and violence are major killers of children throughout the world, responsible for about 950,000 deaths in children and young people under the age of 18 years annually. Unintentional injuries account for almost $90 \%$ of these cases. They are the leading cause of death for children aged $10-19$ years. Road traffic injuries alone are the leading cause of death among 15 - 19 year olds and the second leading cause among $10-14$ year olds. In addition to the deaths, tens of millions of children require hospital care for non-fatal injuries. Many are left with some form of disability, often with lifelong consequences. Global road traffic death rate is 10.7 per 100,000 population with South-East Asia 
death rate being 7.4 while the African region is 19.9. Child pedestrians are the largest category of children involved in road traffic crashes (WHO, 2008). In developed countries, traffic accidents are the leading cause of severe childhood injuries (Tursz \& Gerbouin-Rerolle, 2001). Most of these are caused to children as motor vehicle passengers, followed closely by accident to child pedestrians (CAPT, 2002).

Rosenbloom et al. (2008) unobtrusively studied 269 children between the ages of seven and 11 where 185 crossed a crosswalk without an accompanying adult and 74 were accompanied by an adult. Of the 74 accompanied children, 20 held hands with the adult. For each child observed, four unsafe behaviours were taken note of - not stopping at the kerb, not looking before crossing, attempting to cross when a car was nearing and running across the road. A Chi-Square test revealed that not looking was the most prevalent unsafe behaviour, followed by the combination of not looking and not stopping, and then, not stopping before crossing. Children accompanied by an adult committed more unsafe behaviours. From these children, more unsafe behaviours were committed amongst those not holding hands with the adult.

In another child road crossing study, Oxley et al. (2008) suggested that Australian children predominantly made decisions based on the distance gap of vehicles and that, younger children (6-7 year old) were 12 times more likely than older children ( $8-10$ year olds) to make critically incorrect crossing decisions. In addition, poor performance on all tests of functional skills was associated with a higher likelihood of critically incorrect crossing decisions. In a logistic regression modelling, 'at-risk' children were identified as younger children, those with poorer perceptual, atten- tional and cognitive skills and those with lower traffic exposure.

A study by Rivara et al. (1991) in Seattle-USA, revealed that only one in three children stopped at the kerb before crossing whereas one in four children looked for cars before stepping off the kerb.

A study by Strukcinskiene (2010) in which 403 boys and 531 girls, aged 10 to 19 years participated, showed $16.8 \%$ school children were injured in traffic accident, most of them once $(71.3 \%)$. The survey revealed that children's road safety behaviour was not always acceptable in accordance with road safety factors. In most cases, the girls behaved significantly more safely in road traffic compared with boys.

Children are at highest risk of pedestrian collision, most likely due to the beginning of independent unsupervised travel at a time when their road strategies, skills and understanding are not yet fully developed. Between 2001 and 2005, an average of 310 (2001 - 259; $2002-285 ; 2003-312 ; 2004-389$ and 2005 - 305) children were killed annually through traffic injuries in Ghana (Afukaar \& Ackaah, 2006). This study showed that Children, particularly school-age children, were the group at greatest risk. "The special vulnerability of the 4 to 9 -year-old age group may in part be explained by the lack of exposure in young children and the greater developmental skills in older ones. Generally, more boys (55\%) died through traffic crashes than girls $(45 \%)$, with children in the age groups of $7-9$ and $4-6$ being the most victims. In Ghana, slightly over one out of every four persons killed or seriously injured in traffic crashes is a child pedestrian of school going age. The early school age child appears to represent a "window of vulnerability" in which the skills needed to safely handle traffic exceed the abilities of the 
child at this developmental age" (Afukaar \& Ackaah, 2006).

A study by Afukaar \& Agyemang (2006) on the travel pattern of urban school children in the Kumasi Metropolis showed that most school children travelled to school by walking $(51 \%)$, by private car $(21 \%)$ or by shared taxi (16\%). The study also revealed that $71 \%$ of school children in public schools attended school by walking as against $26 \%$ in the private schools. It said that on the average, the distance any child traveled to school was $2.6 \mathrm{~km}$ but those in private schools travelled much longer, in the region of 2.2 times the distance travelled by those in public schools. While shorter distances less than $3 \mathrm{~km}$ were made by walking, motorised transport was the preferred modal choice for distances greater than $5 \mathrm{~km}$.

This study sought to observe the road use behaviour of pupils of public primary schools in the Ablekuma South Circuit of Ghana Education Service in the Accra Metropolis. The study is a contribution to knowledge in the area of child pedestrian road safety and may be useful as a guide for further research. It has provided information on how children behave while walking along and crossing the road in the Ablekuma South Education Circuit of Metropolitan Accra. The results may be useful to the Metropolitan Assembly when deciding on interventions aimed at child road safety in study area. Again, the results may serve as a yardstick for the National Road Safety Commission and other stakeholders in the planning and improvement of child road safety education.

The study was limited to five variables which did not include road-side walk/ pedestrian walkway use, since most of the study spots did not have pedestrian walkways. A potential limitation to this study was that the unobtrusive observations were done only once in the vicinity of the schools and thus may not be representative of the child's street-crossing performance elsewhere. However, these were naturalistic observations in which the children did not know they were being observed. Thus, the authors believe the data to be a far more accurate assessment of true skills than testing children in the classroom or simulated setting as had been done by others.

\section{Experimental}

The Setting The City of Accra has an estimated 4.5 million people residing in it and over 1 million visitors operating there for various businesses daily. Metropolitan Accra has a total land size of 200 square kilometres and is made up of six sub-metros namely Okaikoi, Ashiedu Keteke, Ayawaso, Kpeshie, Osu Klotey and Ablekuma. Primary school enrolment in the Accra metro area had been estimated to be 101,531 (49,407 boys and 52,124 girls). The Ablekuma South area has a total of 14,804 pupils out of which 7,250 are boys and 7,554 are girls (Ministry of Local Government and Rural Development, 2015).

\section{Data Collection and Study Variables}

The study was an unobtrusive observational one. Unaccompanied primary 1 - 6 school pupils, averagely aged $6-13$ years, were targeted. Five behaviours were graded: walking while crossing the road; stopping at the kerb; looking left-right-left before crossing the road; keep looking while crossing the road and facing traffic while walking along the road. Zebra crossing use was not considered because, some of the crossing points did not have them. Sites chosen for the observation of pupils did not include those protected by traffic wardens/ crossing guards, as pupils' behaviour could have been influenced in those sites. 
Eight public primary schools/cluster of schools were randomly selected from the Ablekuma South Circuit, Ghana Education Service, of the Accra Metropolis. Approximately 110 pupils were observed from each primary school/cluster for the behaviours mentioned above. In all, 16 observation sites close to the entrance of the schools were used. Each Pupil seen either going to or returning from school was graded, whether they walked as individuals or in groups. Pupils observed were therefore not randomly selected.

The widely dispersed selected schools were: Abossey-Okai R/C; Hijaz Islamic, Korle $\mathrm{Bu}$; St. Mary's, Korle Gonno; Star of the Sea,
Dansoman; Salvation Army, Laterbiokorshie; Gbegbeyise Methodist, Dansoman; Mataheko Cluster; and Korle Gonno Cluster, Mamprobi.

These randomly selected primary schools/cluster had a total pupil population of 4,973 out of which $882(18 \%)$ unaccompanied pupils were unobtrusively observed while on their way to and/or from school (i.e. between 06:15 - 08:00GMT; 11:30 - 13:00GMT and $16: 30-18: 00 \mathrm{GMT})$, from $9^{\text {th }}$ to $24^{\text {th }}$ June, 2008. Peak times for vehicular traffic at all study sites were 06:15 - 08:00GMT and 16:30 - 18:00GMT. The sample size is consistent with the proposition of Watson (2001) on sample size determination.

TABLE 1

Definition of behaviours/variables

\begin{tabular}{lll}
\hline Variable & Score & Definition \\
\hline Walking & 0 & Run while crossing \\
Stopping & 1 & Walked while crossing \\
& 0 & Did not stop at the kerb before entering street \\
Looking & 1 & Stopped at the kerb before entering street \\
(L-R-L) & 0 & Did not look left-right-left before crossing \\
Keep Looking & 0 & Did not keep looking for traffic while crossing \\
(L-R-L) & 1 & Kept looking for traffic while crossing \\
Facing Traffic & 0 & Walked with back facing on-coming traffic \\
\hline
\end{tabular}

As shown in Table 1, behaviours were scored " 0 " if not present and " 1 " if present. At each location, two observers unobtrusively studied each child's road use behaviour to ensure reliability and accuracy and in about $99 \%$ of the cases, they agreed. Data obtained from the survey were analysed using Microsoft Excel spreadsheet and quantitative statistical procedure at $95 \%$ Confidence Interval. 


\section{Results and discussion}

TABLE 2

Frequency and percentages of children with correct behaviour

\begin{tabular}{llll}
\hline Behaviour / Variable & $\begin{array}{l}\text { Correct Behaviour } \\
(\mathbf{n = 8 8 2})\end{array}$ & $\begin{array}{l}\text { Boys with Correct Be- } \\
\text { haviour }(\mathbf{n = 4 9 5 )}\end{array}$ & $\begin{array}{l}\text { Girls with Correct } \\
\text { Behaviour }(\mathbf{n}=\mathbf{3 8 7})\end{array}$ \\
\hline Walk & $674(76.4 \%)$ & $381(77 \%)$ & $293(75.7 \%)$ \\
Stop & $668(78 \%)$ & $377(76.2 \%)$ & $311(80.4 \%)$ \\
Look (L-R-L) & $652(73.9 \%)$ & $290(58.6 \%)$ & $362(93.5 \%)$ \\
Keep Looking & $170(19.3 \%)$ & $57(11.5 \%)$ & $113(29.2 \%)$ \\
Face Traffic & $548(62.1 \%)$ & $268(54.1 \%)$ & $280(72.4 \%)$ \\
$\begin{array}{l}\text { Average correct behaviour } \\
(\%)\end{array}$ & $61.9 \%$ & $55.5 \%$ & $70.2 \%$ \\
& & & \\
\hline
\end{tabular}

TABLE 3

Two-by-two table analysis of road use behaviour by gender

\begin{tabular}{l|l|lllll}
\hline $\begin{array}{l}\text { Behaviour } \\
\text { [(Boys:n=495) }\end{array}$ & (Girls: & $\begin{array}{l}\text { Correct } \\
\text { Behaviour } \\
\text { n=387)] }\end{array}$ & $\begin{array}{l}\text { Incorrect } \\
\text { Behaviour }\end{array}$ & $\begin{array}{l}\text { Chi-square - } \chi^{2} \\
\text { (p-values; 95\%CI) }\end{array}$ & Odds Ratio & $\begin{array}{l}\text { Relative } \\
\text { Risk }\end{array}$ \\
\hline Walking & Boys & $381(77 \%)$ & $114(23 \%)$ & $0.191(0.66203)$ & 0.93265 & 0.94813 \\
& Girls & $293(75.7 \%)$ & $94(24.3 \%)$ & & \\
Stopping & Boys & $377(76.2 \%)$ & $118(23.8 \%)$ & $2.233(0.13508)$ & 1.28082 & 1.21384 \\
& Girls & $311(80.4 \%)$ & $76(19.6 \%)$ & & 1.24971 \\
Keep & Boys & $57(11.5 \%)$ & $438(88.5 \%)$ & $43.652(0.00000)$ & 3.16900 & \\
Looking & Girls & $113(29.2 \%)$ & $274(70.8 \%)$ & & \\
Looking & Boys & $290(58.6 \%)$ & $205(41.4 \%)$ & $137.66(0.00000)$ & 10.23010 & 0.64102 \\
$($ L-R-L) & Girls & $362(93.5 \%)$ & $25(6.5 \%)$ & & & 1.65861 \\
FacingTraffic & Boys & $268(54.1 \%)$ & $277(45.9 \%)$ & $50.18(0.00000)$ & 2.70472 & \\
\hline
\end{tabular}

\section{Walking}

When crossing the road, 674 out of 882 pupils did so by walking, representing $76.4 \%$ correct behaviour. There were 1.07 greater odds of girls running instead of walking than they were for boys. On the other hand, there were 1.05 greater probabilities (relative risk) of girls running as opposed to walking when crossing the road than they were for boys. In spite of these nominal differences, a chi-square test revealed that there was no significant difference in gender behaviour $\left(\chi^{2}=0.191 ; \mathrm{p} \leq 0.662031\right.$; $95 \% \mathrm{CI})$. A little over three in four children (3.1) averagely walked while crossing, implying $23.6 \%$ children exhibited risky behaviour. 


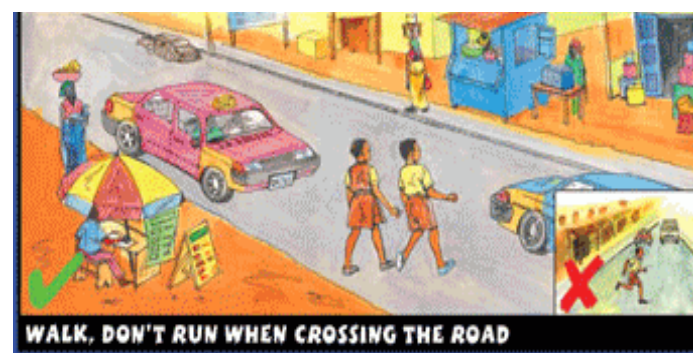

Fig. 1: Correct mode of crossing the road.

\section{Stopping at the kerb}

The proportion of correct behaviour exhibited in stopping at the curb by pupils from the selected schools represented 78\% (Table 2). There were 1.28 greater odds of boys not stopping at the kerb before crossing the road than they were for girls. In terms of relative risk, there were 1.21 greater probabilities of boys not stopping at the kerb than they were for girls (table 3). However, there was no significant difference in gender behaviour $\left(\chi^{2}=2.233 ; \mathrm{p}\right.$ $\leq 0.13508$; $95 \% \mathrm{CI})$. The observed variations were therefore by chance. Averagely, a little over two in three children (2.34) stopped at the kerb before crossing the road. There were $22.8 \%$ of the children who exhibited risky behaviour that predisposed them to RTI or death. In a similar study by Rivara et al. (1991), one in three children stopped at the kerb.

\section{Looking left-right - left}

In terms of looking left-right-left before crossing the road, 652 out of 882 pupils did so correctly, representing $73.9 \%$ (Table 2). There were 10.23 greater odds of boys not looking left-right-left before crossing the road than they were for girls. With respect to relative risk, there were 0.64 greater probabilities of boys not looking left-right-left before crossing the road than they were for girls (Table $3)$. The chi-square test revealed that there was statistically significant difference in gender behaviour $\left(\chi^{2}=137.66 ; \mathrm{p} \leq 0 ; 95 \% \mathrm{CI}\right)$. Almost three in four children (2.96) looked for cars before stepping off the kerb. This implies 26.1\% of them exhibited risky behaviour which predisposed them to either injury or death. In the Seattle study by Rivara et al. (1991), one in four children looked for cars. Rosenbloom et al. (2007) also found that not looking was the most prevalent unsafe behaviour, followed by the combination of not looking and not stopping, and then, not stopping before crossing.

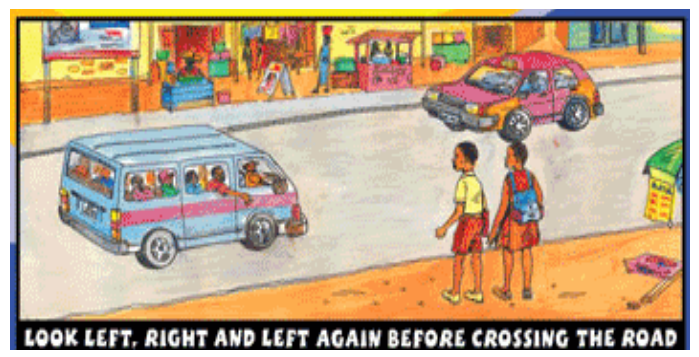

Fig. 2: Stopping at the kerb and looking.

\section{Keep looking left-right-left}

With regard to keeping looking left-right-left while crossing the road, 170 out of $882 \mathrm{pu}-$ pils, representing $19.3 \%$ exhibited correct behaviour. There were 3.17 greater odds of boys not to keep looking left-right-left while crossing the road than they were for girls. Again, there were 1.25 greater probabilities of boys not to keep looking left-right-left than they were for girls. The chi-square test revealed a significant difference in gender behaviour $\left(\chi^{2}\right.$ $=43.652 ; \mathrm{p} \leq 0 ; 95 \% \mathrm{CI})$. Less than 1 in 4 children (0.77) kept looking while crossing.

\section{Facing traffic}

For Pupils walking along the road, 548 out of 882 , representing $62.1 \%$ did so facing on-coming traffic. There were statistically significant difference in gender behaviour $\left(\chi^{2}=50.18 ; p \leq 0\right.$; 
$95 \% \mathrm{CI})$. There were 2.7 greater odds of boys not facing on-coming traffic while walking along the road than they were for girls. Also, there were 1.66 greater probabilities of boys not facing on-coming traffic than they were for girls.

Generally, the road safety behaviour of girls was more acceptable than that of boys. This is consistent with the findings of Strukcinskiene (2010) which observed in most cases that girls behaved significantly more safely in road traffic compared with boys. The behavior of children on the road may not be consistent since they could be distracted from doing the same things every time. Other authors have reported improvements in child pedestrian performance (Yeaton et al., 1978; Rivara et al., 1991) or a reduction of injuries (Bloomberg et al., 1983; Rivara et al., 1991) following pedestrian skills training. However, these results are either unduplicated or internally inconsistent. It is clear that despite a large effort to improve the pedestrian behavior of children, only modest changes can be achieved (Rivara et al., 1990; Rivara et al., 1991).

\section{Conclusion and recommendations}

From the study, the most unsafe behaviours were shirking looking left-right-left while crossing the road followed by not encountering on-coming vehicles.

The road use behaviour of girls had been found to be more acceptable than that of boys. Therefore, boys were guiltier of unsafe behaviour than girls in all cases except in road crossing where more girls run instead of walking but these variations were only due to chance.
Road safety education (RSE) in Schools and Communities is hereby recommended. Provision of readers and homework books with emphasis on looking while crossing; facing on-coming traffic; looking left-right-left before crossing; walking while crossing and stopping at the kerb.

Road safety clubs and drama groups could be established in schools as well as encouraging the visit of "people crippled in road crashes' to schools as part of RSE programmes. 'Puppet shows' can be used to introduce topics on road safety in primary schools and Communities along major roads. Traffic Wardens could also be employed at crossings and school junctions to ensure children cross roads safely.

\section{Acknowledgements}

This study was funded in part by Amend.org and the authors are very grateful to the Executive Director, Mr. Jeffery Witte, and staff of the Ghana Country Office, especially, Muhsin Bako and Kinsley Hoene Amoako. The figures used for illustration were also adapted from Amend.org.

\section{References}

AfukaAr, F. K. \& AckaAh, W. (2006) Fatal Road Traffic Accidents Involving Children,Consultancy Report on Transport Sector Programme Support, Phase II (TSPS), CARLBRO a/s, submitted to National Road Safety Commission by CSIR-Building and Road Institute, Ghana.

Afukaar, F. K. \& Agyemang, W. K. (2006) Travel Pattern of Urban School Children in the Kumasi Metropolis, Journal of Building and Road Research, Ghana 10 (1 \& 2), 3 - 12.

Bloomberg, R. D., Preusser, D. F., Hale, A. \& Leaf, W. A. (1983) Experimental Field Test of Proposed Pedestrian Safety Messages, Volume II, Child Messages. Washington, DC: US Dept 
of Transportation, National Highway Traffic Safety Administration; DOT HS-806-522.

CHILD ACCIDENT PREVENTION TRUST (CAPT). (2002) Child Pedestrians, CAPT Fact Sheet, London

MINISTRY OF LOCAL GOVERNMENT AND RURAL DEVELOPMENT, GHANA.http:// www.ghanadistricts.com/Home/District/242 (accessed on October 17, 2015)

Oxley, J.A., Congiu, M., Whelan, M., D'elia, A. \& Charlton, J. (2008) The Impacts of Functional Performance, Behaviour and Traffic Exposure on Road-Crossing Judgements of Young Children. Annu Proc Assoc Adv Automot Med. 51, 81-96.

Rivara, F. P., Bergman, A. B. \& Drake, C. (1989) Parental Attitudes and Practices toward Children as Pedestrians. Pediatrics 84, 1017 - 1021.

Rivara, F. P. (1990) Child Pedestrian Injuries in the United States: Current Status of the Problem, Potential Interventions and Future Research Needs, AJDC 144, $692-696$.

Rivara, F. P., Booth, C. L., Bergman, A. B., Rogers, L. W. \& Weiss, J. (1991) Prevention of Pedestrian Injuries to Children: Effectiveness of a School Training Programme. Pediatrics 88 (4), $770-775$.
Rosenbloom, T., Ben-Eliyahu, A. \& Emrodov, D. (2008) Children's Crossing Behavior with an Accompanying Adult. Safety Science. 46, 1248 - 1254. 10.1016/j.ssci.2007.07.004.

Strukcinskiene, B. (2010) Association between child road safety behaviour and prevention activities, Inj Prev. 16, A61 - A62 doi:10.1136/ ip.2010.029215.224

THE GLOBAL BURDEN OF DISEASE: 2004 Update. (2008). Geneva, World Health Organization. (https://www.who.int/healthinfo/ global_burden_disease/GBD_report_2004update_full.pdf?ua=1)

Tursz, A. \& Gerbouin-Rorolle, P. (2001) Les Accidents de L'enfant en France: Quelle Préventions, Quelle Evaluation? Rapport INSERM, Paris.

Watson, J. (2001) How to Determine a Sample Size: Tipsheet \#60, University Park, PA: Penn State Cooperative Extension.।

Yeaton, W. H. \& Bailey, J. S. (1978) Teaching Pedestrian Safety Skills to Young Children: an Analysis and One-Year Follow-Up, J Appi Behav Anal. 11, 315 - 329.

Received 21 Jan 20; revised 03 Aug 20. 